\title{
Characterization of Emissions from a Non-Ideal Spray Polyurethane Foam Sample Letter Report to U.S. Consumer Product Safety Commission Interagency Agreement CPSC-I-13-0016 MOD 1
}

Dustin Poppendieck Mengyan Gong Lauren Lawson Steve Emmerich

This publication is available free of charge from: http://dx.doi.org/10.6028/NIST.IR.8131 


\title{
Characterization of Emissions from a Non-Ideal Spray Polyurethane Foam Sample
}

Letter Report to U.S. Consumer Product Safety Commission Interagency Agreement CPSC-I-13-0016 MOD 1

\author{
Dustin Poppendieck \\ Mengyan Gong \\ Lauren Lawson \\ Steve Emmerich \\ Engineering Laboratory \\ Energy and Environment Division
}

This publication is available free of charge from: http://dx.doi.org/10.6028/NIST.IR.8131

April 2016

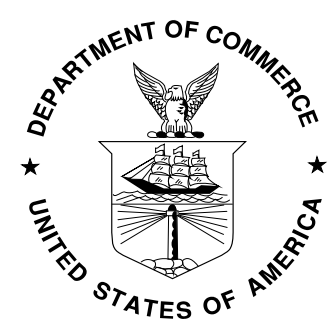

U.S. Department of Commerce

Penny Pritzker, Secretary

National Institute of Standards and Technology Willie May, Under Secretary of Commerce for Standards and Technology and Director 


\section{Objective}

This report summarizes the National Institute of Standards and Technology (NIST) activities under the FY2014 interagency agreement between the Consumer Product Safety Commission (CPSC) and NIST. The objective of that agreement is to develop testing and measurement protocols for determining the quantities and properties of compounds released from spray polyurethane foam (SPF) as it is applied in residential settings. Specifically, this report reviews data collected from two SPF samples associated with residential complaints supplied by CPSC.

\section{Background}

Many homeowners are using insulating products, such as SPF, at a growing rate, and many government programs recommend their use in order to increase the energy efficiency of residences and other buildings. Retrofitting or use of foam insulation in new construction is also supported in the United States by Federal efforts, such as tax incentives, and programs like Environmental Protection Agency (EPA) Energy Star and Design for the Environment. Because of these programs and other drivers for more efficient buildings, the insulation foam industry expects significant growth in the use of their products over the coming years. ${ }^{1,2}$

SPF is used as both an insulation and an air sealant. It is formed onsite via an exothermic chemical reaction between A-side and B-side chemicals. The A-side typically consists of monomeric or polymeric methylene diphenyl diisocyanate. Polyols are part of the B-side chemicals, which also include amine and/or metal catalysts, blowing agents, surfactants, and flame retardants. Amine and/or metal catalysts are used to promote the reaction between polyols and A-side chemicals, which help polyurethane foam cells develop sufficient strength to maintain their structure and resist collapsing.

CPSC, along with EPA and other federal agencies, has received a number of complaints regarding health effects coinciding with the installation of SPF in homes. ${ }^{3}$ These residents have complained about a multitude of health effects including severe respiratory irritation, breathing difficulties, dizziness and nausea. In some cases, the reported effects are so severe that consumers report that they can no longer live in their homes. ${ }^{4}$ These health effects are typically reported to occur several days to months following the SPF installation in the home.

One hypothesis is that the consumer complaints related to SPF are the result of applying SPF in a non-ideal manner. Non-ideal conditions include off-ratio (A-side to B-side) application, low substrate temperature application, and wrong nozzle pressure and temperature. To date there is minimal data on emissions from non-ideal foam (Poppendieck et al., 2016). This report provides emission data on two SPF samples from a residential building in which the occupants have complained about the SPF. As per the NIST/CPSC agreement this foam will be described in this report as non-ideal foam. However, no details are available about the preparation and application of this specific foam.

\footnotetext{
${ }^{1}$ http://www.businesswire.com/news/home/20130717005300/en/SPF-Insulation-Demand-Growth-CreatingInvestment-Opportunities\#.U2p6n_ldXzg

2 http://sprayfoamsupply.com/foam-insulation-to-gobble-up-market-share-by-2017/

${ }^{3}$ http://www.saferproducts.gov/Search/Result.aspx $? d m=0 \& q=$ Spray + foam + insulation\&srt $=0$.

${ }^{4}$ http://www.saferproducts.gov/Search/Result.aspx?dm=0\&q=Spray+foam + insulation\&srt $=0$.
} 
The ASTM Indoor Air Quality (D22.05) subcommittee develops standard test methods and protocols to determine the emissions rates from materials. Currently a new standard for measuring the emissions of chemicals from SPF using micro-chamber apparatus is being developed (WK 40293). For this report, the draft version of this test method (balloted Spring 2016) was used to quantify emissions from foam described as non-ideal that was submitted by CPSC to NIST for testing.

\section{Methods}

Two samples of closed cell foam from the same spraying event, but applied at two different locations in the house, were delivered to NIST on February 22, 2016. The foam was stored in room temperature coolers between delivery and testing. Preliminary testing commenced on February 24, 2016 conducted to determine the chemicals present in the foam and the required sampling times. After preliminary sampling, newly identified chemicals were acquired and standards were made. Quantification testing began on March 14, 2016.

Density of the foam was determined by cutting $3.0 \mathrm{~cm}( \pm 0.1 \mathrm{~cm})$ cubes from the $15 \mathrm{~cm} \mathrm{x} 33 \mathrm{~cm}$ x $45 \mathrm{~cm}$ sample. Triplicate cubes were randomly taken from the sample. Each cube was weighed to the nearest mg. A machined cutting tool was used to cut six SPF samples to fit tightly within Markes 125 small micro-chambers (44 mL chambers) according to ASTM D7859-e13. Three chambers were filled with SPF from location 1, and three chambers were filled with SPF from location 2. The top of each sample was removed to make the samples uniformly flat. Samples were cut to a depth of $24 \mathrm{~mm}$, leaving $6 \mathrm{~mm}$ headspace.

The $44 \mathrm{~mL}$ chambers were operated for 200 hours at a temperature of $35.2{ }^{\circ} \mathrm{C}$ (standard deviation $0.4^{\circ} \mathrm{C}$ ) with a $24.1 \mathrm{~mL} / \mathrm{min}$ (standard deviation $1 \mathrm{~mL} / \mathrm{min}$ ) airflow of ultra-high purity air. No moisture was added to the high purity air, resulting in a relative humidity of zero.

Emissions were captured on sorption tubes. Tenax TA sorption tubes were used to capture amine catalysts, flame retardants and other volatile organic compounds, and were subsequently analyzed by gas chromatography/mass spectrometer (GC/MS). Aldehyde analysis is not covered in this report.

Prior to sampling, the Tenax TA tubes were cleaned with ultra-high purity helium for one hour at $315{ }^{\circ} \mathrm{C}$ with a Markes TC-20 tube cleaner. The tubes were attached to the effluent flow of each chamber for $5 \mathrm{~min}$ to $1 \mathrm{~h}$ depending on the estimated concentrations of the target chemicals determined from the preliminary experiments. Samples were taken 2 h, 24 h, 48 h, 96 h, 120 h, $172 \mathrm{~h}$, and $196 \mathrm{~h}$ after samples were placed in the chambers. At each sampling time two sorbent tubes were collected to ensure each chemical sampled was within the standard curve.

Following sample collection, the Tenax TA tubes were spiked with $1 \mu$ g deuterated toluene as an internal standard by injecting liquid solution into a TALBOYS Standard Heatblock. The Tenax TA tubes were thermally desorbed using a Gerstel thermal desorbing system. The set points used for the thermal desorption system and GC/MS are summarized in Table 1. A Rtx-5 Amine column (30.0 m x $250 \mu \mathrm{m} \times 0.50 \mu \mathrm{m})$ was used for compound separation in the GC/MS.

Preliminary work identified the presence of over 80 different chemicals after heating SPF samples to $35^{\circ} \mathrm{C}$ for $24 \mathrm{~h}$ and sampling for 20 minutes. Of these chemicals, 17 were identified with the GC/MS (spectrum match with a quality score greater than 80 ) and had relatively large response areas (over 30 000). These chemicals are listed in Table 2 ranked in order of GC/MS response area. 
Table 1. Summary of thermal desorption and GC/MS parameters.

\begin{tabular}{|c|c|}
\hline Parameter & Setting \\
\hline \multicolumn{2}{|c|}{ Thermal Desorption Unit (TDU) } \\
\hline Hold & $30^{\circ} \mathrm{C}$ for $0.5 \mathrm{~min}$ \\
\hline Ramp & $360^{\circ} \mathrm{C} \mathrm{min}^{-1}$ \\
\hline Final & $300^{\circ} \mathrm{C}$ for $8 \mathrm{~min}$ \\
\hline \multicolumn{2}{|c|}{ Cooled Injection System (CIS) } \\
\hline Hold & $-120^{\circ} \mathrm{C}$ \\
\hline Ramp & $12{ }^{\circ} \mathrm{C} \mathrm{s}^{-1}$ \\
\hline Final & $275^{\circ} \mathrm{C}$ for $8 \mathrm{~min}$ \\
\hline \multicolumn{2}{|l|}{ Oven } \\
\hline Flow & $1 \mathrm{~mL} \min ^{-1}$ \\
\hline Hold & $40^{\circ} \mathrm{C}$ for $2 \mathrm{~min}$ \\
\hline Ramp & $20{ }^{\circ} \mathrm{C} \min ^{-1}$ \\
\hline Final & $300^{\circ} \mathrm{C}$ for $2 \mathrm{~min}$ \\
\hline
\end{tabular}

The first seven chemicals in Table 2 were targeted for the quantification experiment, since they had the largest response areas (over 100 000) in the preliminary testing. Chemical standards (Table 2) were purchased for target compounds. Neat chemical standards were prepared by dilution in methanol. Neat triethylenediamine was purchased but was not received in time for the quantification experiment. Nevertheless, this chemical's relative response ratio (area response for quantitation ion of the chemical divided by the area response for quantitation ion of the deuterated toluene) is reported.

Table 2. Chemicals identified in preliminary sampling (ranked in order of largest GC/MS response area)

\begin{tabular}{|lrrl|l|} 
& \multicolumn{2}{c}{ CAS } & \multicolumn{1}{l|}{ Average } \\
Chemical & Number & Acronym & \multicolumn{1}{l|}{ Linear RSQ } \\
\hline Triethylenediamine & $280-57-9$ & TEDA & \multicolumn{1}{l|}{ N/A } \\
\hline 1,4-Dioxane & $123-91-1$ & D & 0.999 \\
\hline Propane, 1,2-dichloro- & $78-87-5$ & DCP & 0.992 \\
\hline Piperazine, 1,4-dimethyl & $106-58-1$ & DMP & 0.991 \\
\hline Tris-(1-chloro-2-propyl) phosphate & $13674-84-5$ & TCPP & 0.989 \\
\hline Benzene, 1,2-dichloro & $95-50-1$ & DCB & 0.996 \\
\hline 1,3-Dioxolane, 2-ethyl-4-methyl & $126-39-6$ & DEM & 0.993 \\
\hline Cyclotetrasiloxane, octamethyl- & $556-67-2$ & & N/A \\
\hline 1,4-Dioxane, 2,5-dimethyl- & $15176-21-3$ & & N/A \\
\hline Octane & $111-65-9$ & & N/A \\
\hline 1-Propanol, 2-chloro- & $19210-21-0$ & & N/A \\
\hline Piperazine, 1,2,4-trimethyl- & $120-85-4$ & & N/A \\
\hline Azulene & $275-51-4$ & & N/A \\
\hline Benzaldehyde & $100-52-7$ & & N/A \\
\hline 1,4-Dioxin, 2,3-dihydro- & $493-09-4$ & & N/A \\
\hline 2-Butenal, 2-methyl-, (E)- & $497-03-0$ & & N/A \\
\hline Benzene & $71-43-2$ & & N/A \\
\hline
\end{tabular}


Standards were spiked onto Tenax TA tubes along with the deuterated toluene internal standard. Chemicals were quantified using the response ratio between target chemical and internal standard for each chemical. Linear standard curves (injected mass versus relative response ratio) were created for each chemical (average RSQ values for each linear curve are shown in Table 1) on a daily basis. Isocyanates were not analyzed as part of this research effort. The chambers were tested prior to the introduction of the foam samples to ensure background concentrations of the chemicals of interest were below the detection limit. Blank Tenax TA tubes were run at least every seven tubes to demonstration the absence of carryover between samples.

\section{Results and Discussion}

Both concentrations and emission rates were determined for the samples. All concentrations and emission rates in this document apply only to micro-chamber conditions. The mass transfer conditions or rates in building systems may not be similar to those experienced in a microchamber. Hence, this data should not be used to predict to full-scale emissions until further research has determined scaling parameters.

\section{Density:}

The average density of the foam from location 1 was $49.8 \mathrm{~kg} / \mathrm{m}^{3}$ (triplicate measurements, standard error $2.6 \mathrm{~kg} / \mathrm{m}^{3}$ ). The density of the foam from location 2 was $33.0 \mathrm{~kg} / \mathrm{m}^{3}$ (triplicate measurements, standard error $2.6 \mathrm{~kg} / \mathrm{m}^{3}$ ). ASTM WK40293 cites the typical density for closedcell SPF as $24 \mathrm{~kg} / \mathrm{m}^{3}$ to $32 \mathrm{~kg} / \mathrm{m}^{3}$ and $6.4 \mathrm{~kg} / \mathrm{m}^{3}$ to $9.6 \mathrm{~kg} / \mathrm{m}^{3}$ for open-cell SPF. The non-ideal foam samples from the test locations had higher densities than measured densities of comparative SPF provided by the American Chemistry Council's Center for the Polyurethanes Industry (CPI): closed-cell foam $\left(30.6 \mathrm{~kg} / \mathrm{m}^{3}\right)$ and open-cell foam $\left(8.6 \mathrm{~kg} / \mathrm{m}^{3}\right)$. Both of the CPI foams were also tested for this work for comparison. These CPI research formulations were developed in 2011 to be representative of SPF then available in the marketplace. The formulations were created for research purposes only and were not optimized to meet the specifications of commercial producers and therefore may not reflect formulations currently available in the marketplace.

\section{Chemicals Present}

In general, the non-ideal foam had a greater number of chemicals present (number of peaks) at greater concentrations (peak height) than previously tested CPI closed-cell foams (Figure 1) (Poppendieck et. al., 2016). Comparison to internal data from four institutions showed that within the chemicals in Table 1, seven had not been previously identified in other foams: 1,2dichlorobenzene, triethylenediamine, 1,2-chloropropanol, 1,2,4-trimethylpiperazine, Azulene, 2,3-dihydro 1,4-dioxin, and 2-methyl 2-butenal. Their presence may be specific to the non-ideal foam or because the published surveys of chemicals emitting from SPF are limited. Of the seven new chemicals, 1,2-dichlorobenzene and triethylenediamine were chosen for quantification due to the large response areas. 


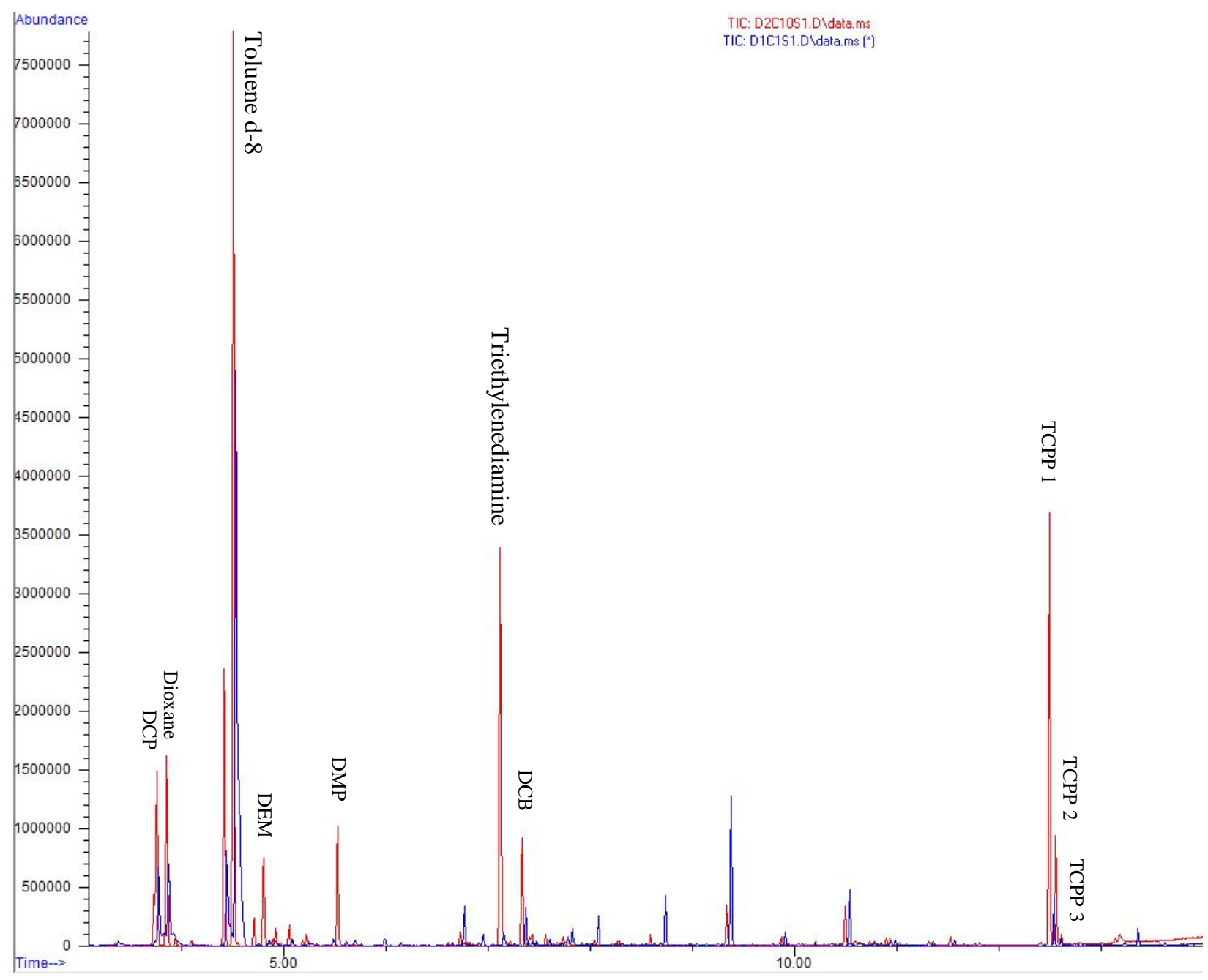

Figure 1. GC/MS comparison of chromatograms from samples at $24 \mathrm{~h}$ from non-ideal foam (red, sampled for $45 \mathrm{~min}$ ) and CPI supplied foam (blue, sampled for 90 minutes). Due to different GC/MS parameters the peaks do not exactly line up for the same chemicals. The horizontal axis is time (min), the vertical axis is abundance of the chemical.

\section{Location Comparison}

In general the samples from the two locations of the same spray event had similar emission profiles (Figure 2). Peaks present in one sample were present in the second sample. For the quantified peaks, the concentrations were typically similar for both samples. Figure 3 shows a typical example of this trend (1,4 dioxane ). However, TCPP concentrations for foam from location 1 were higher for most of the samples (Figure 4). For the remainder of this document, the concentrations and emission rates are presented as an average value from all six chambers, regardless of source location of the SPF . 


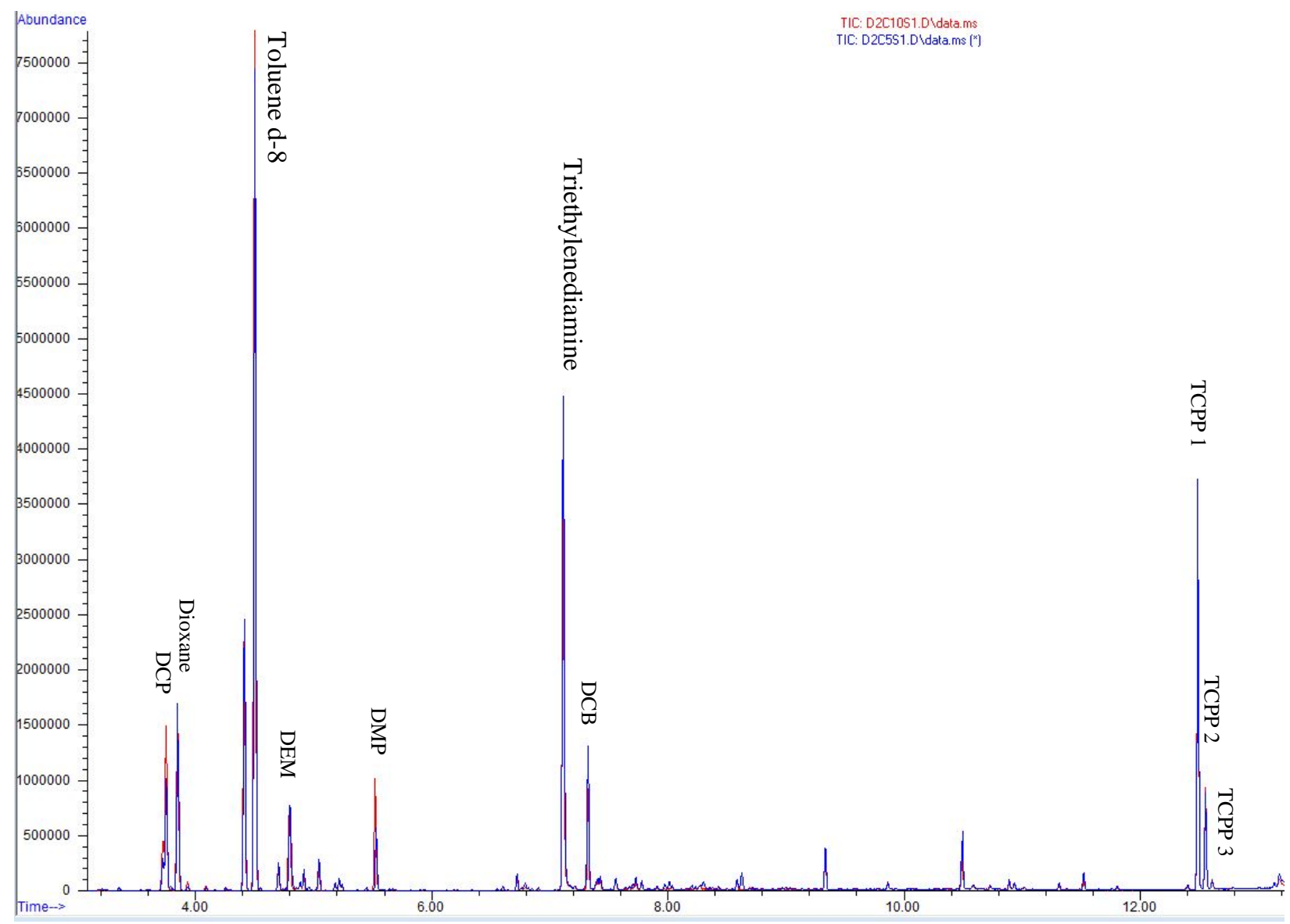

Figure 2. GC/MS comparison of chromatograms from different locations from non-ideal SPF. Blue line is from location 1 and red line is from location 2. The horizontal axis is time (min), the vertical axis is abundance of the chemical.

Micro-Chamber Concentrations

Concentrations of the flame retardant TCPP remained relatively constant for samples taken after 48 hours (Figure 4), while concentrations of other quantified chemicals decreased in a negative exponential manner over time (Figure 5). The response ratio for triethylenediamine also decreased in a negative exponential manner (Figure 6). 


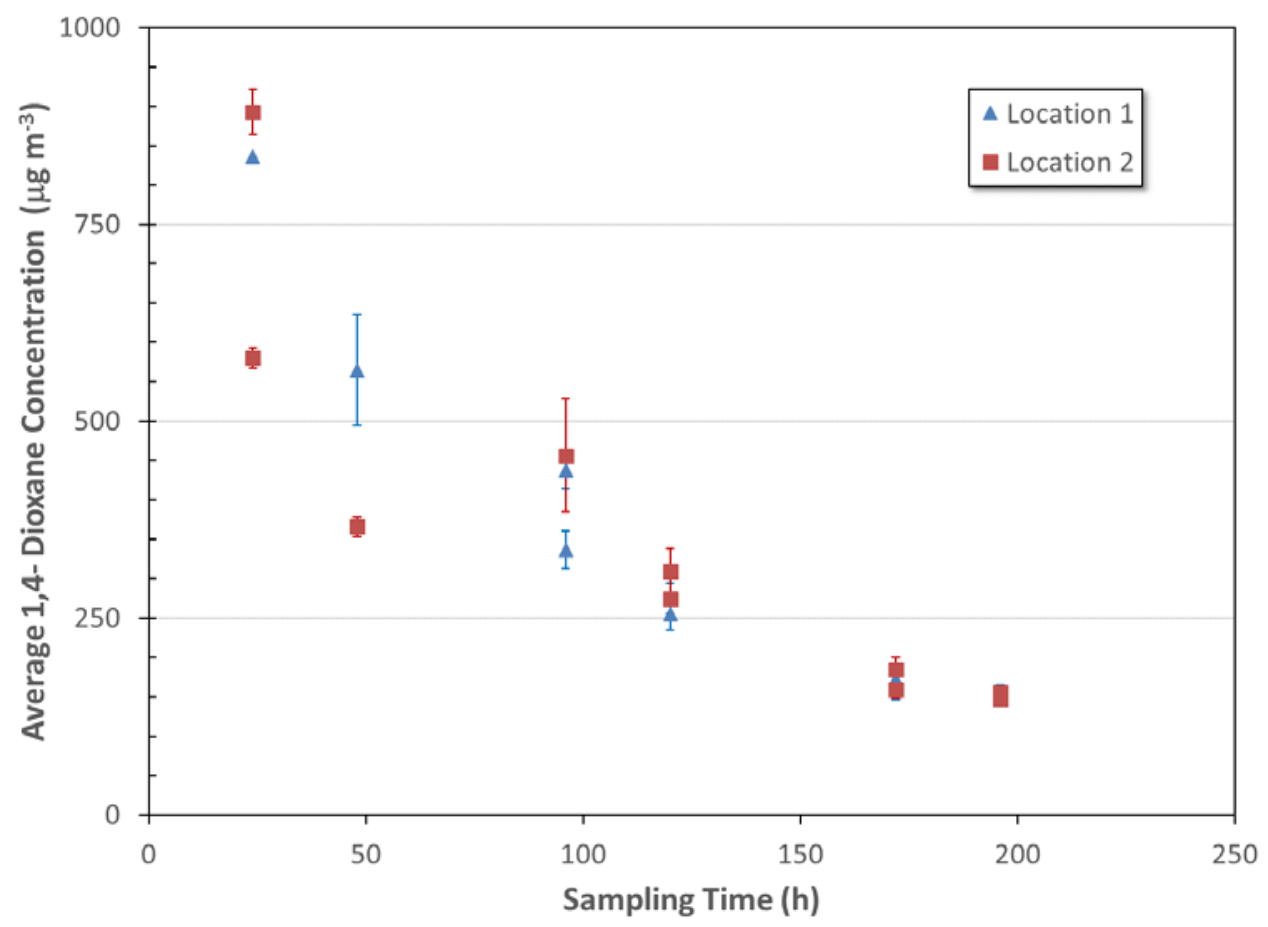

Figure 3. 1,4 Dioxane Concentrations over seven sampling periods. Error bars show the standard error for triplicates at each sampling time.

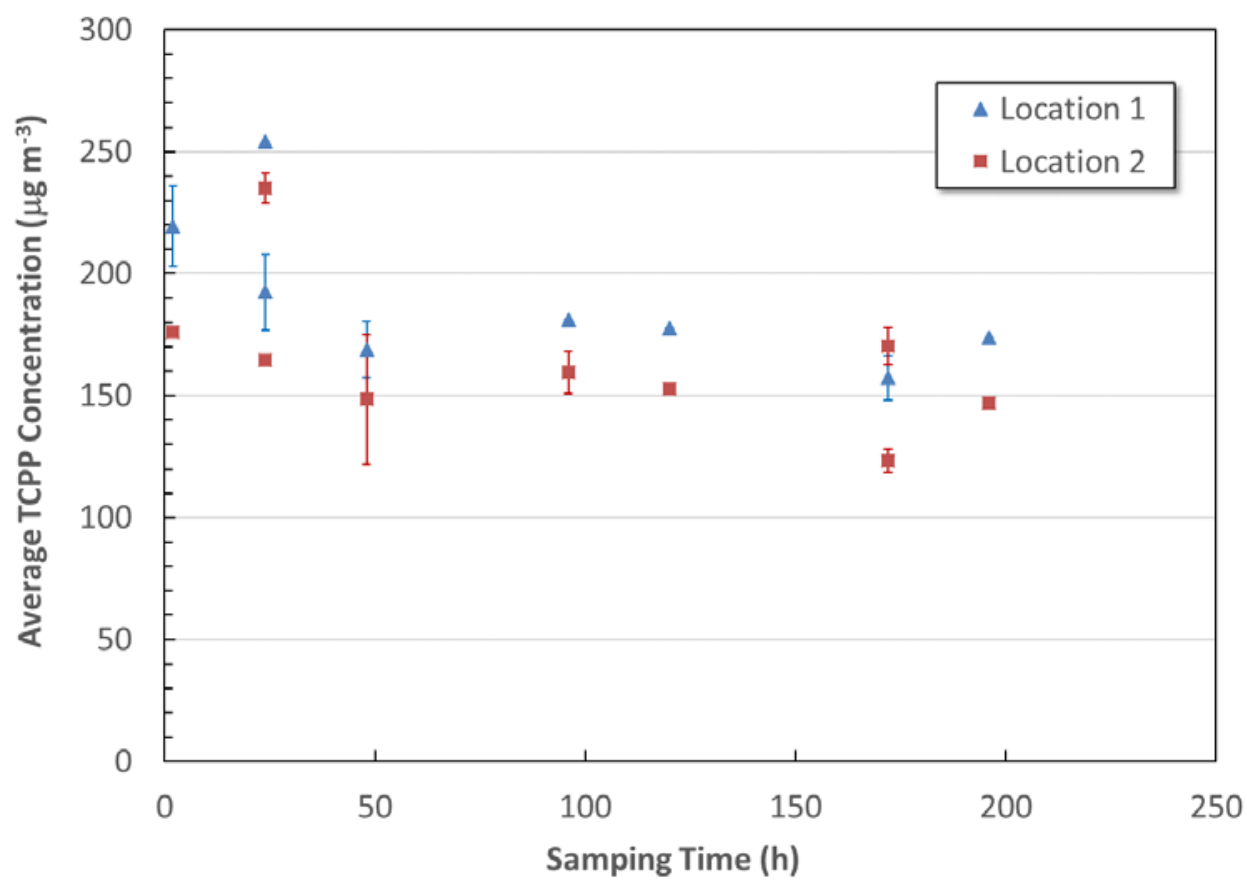

Figure 4. TCPP Concentrations over seven sampling periods. Error bars show the standard error for triplicates at each sampling time. 


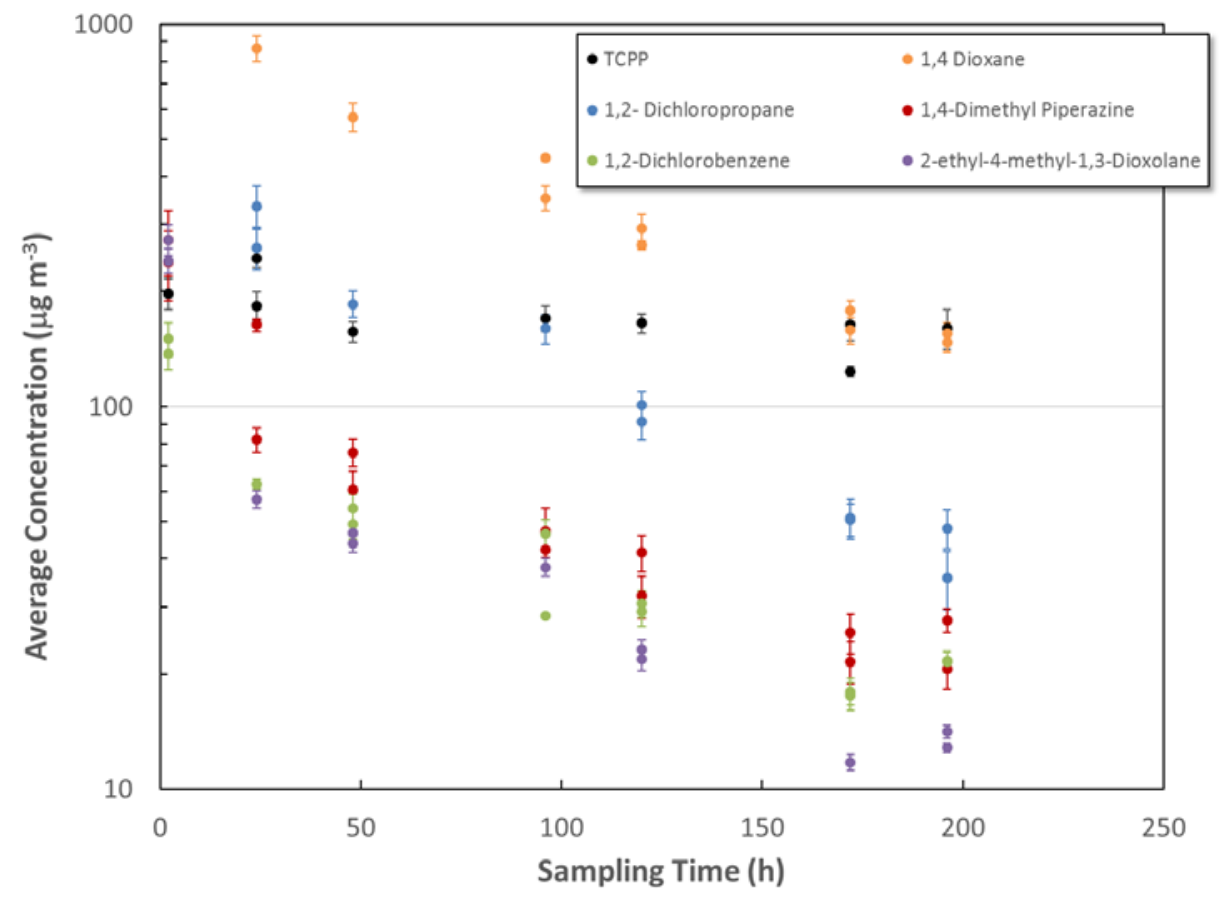

Figure 5. Concentrations of all quantified chemicals over seven sampling periods. Error bars show the standard error for triplicates at each sampling time. Vertical axis is a logarithmic scale.

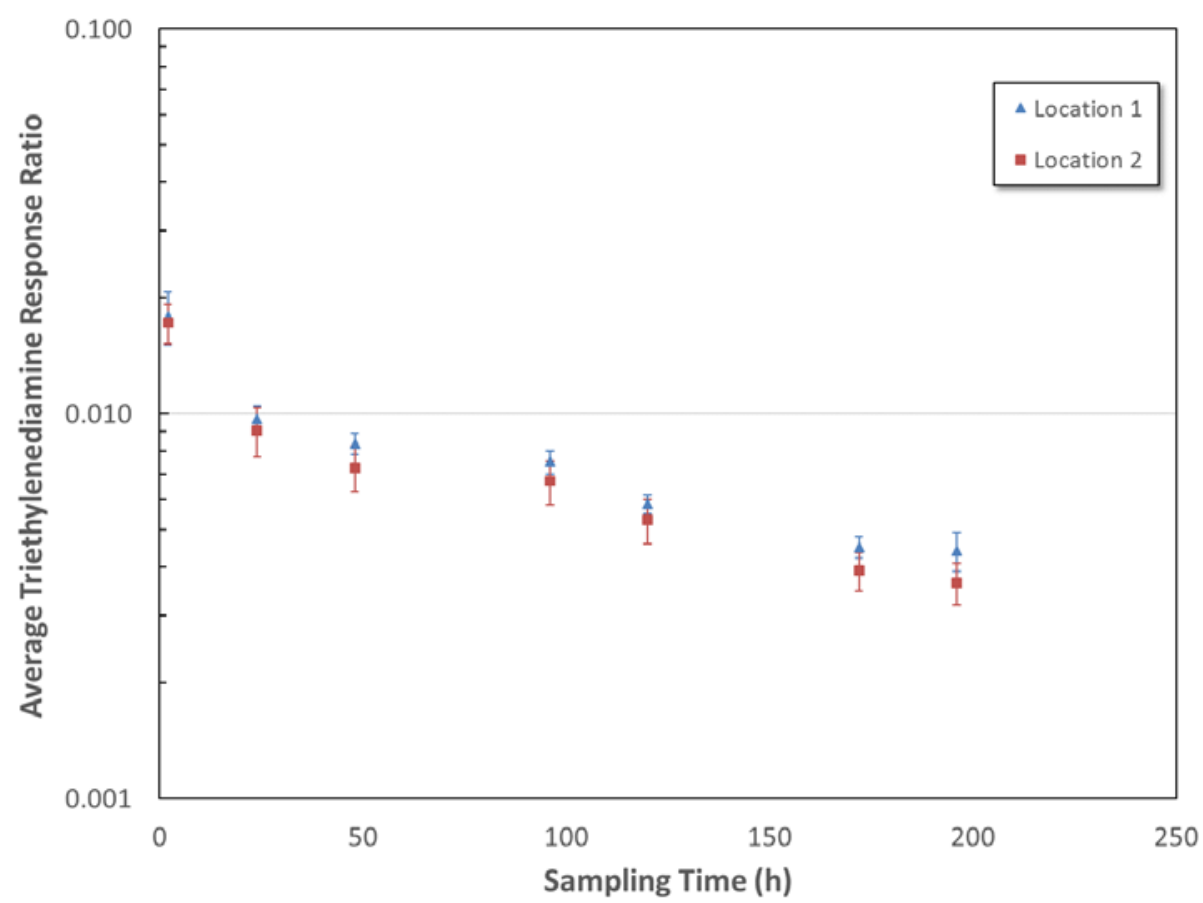

Figure 6. Relative response ratio between triethylenediamine and internal standard. Error bars show the standard error for each sampling time. Vertical axis is a logarithmic scale. 


\section{Micro-Chamber Emission Rates}

The emission rates followed the same trends as the concentrations. The emission rate of all chemicals other than TCPP decreased in a negative exponential manner with time (Figure 7). The TCPP emission rates from the closed cell non-ideal foam followed similar trends compared to previously tested open-cell CPI foam (although a lower value) (Poppendieck et. al., 2016), and were different from previously tested closed-cell CPI foam (red open square values in Figure 8). The emission data from the non-ideal foam were collected in $44 \mathrm{~mL}$ micro-chambers, while the remaining emission rates were collected in $114 \mathrm{~mL}$ micro-chambers. The differing flow rates of the two systems with different chamber sizes $(25 \mathrm{~mL} / \mathrm{min}$ versus $50 \mathrm{~mL} / \mathrm{min}$ ) is not expected to change the shape of the TCPP emission profile to the degree seen in Figure 8. This differing TCPP emission rate profile may be a function of non-ideal foam or the fact that published surveys of chemical emission rates from SPF are limited.

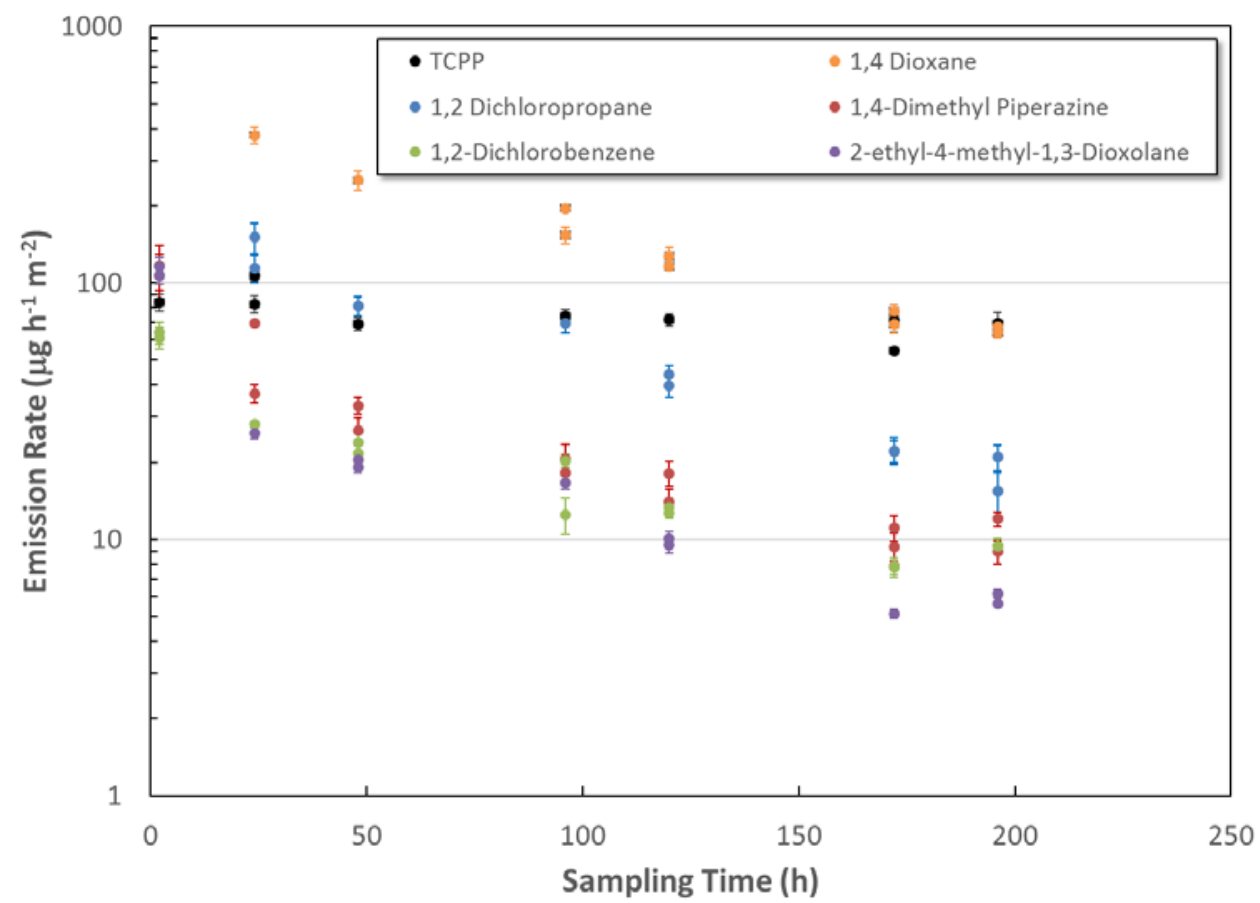

Figure 7. Emission rates for all quantified chemicals. Error bars show the standard error for each sampling time. Vertical axis is a logarithmic scale.

Both 1,4 dioxane and 1,2 dichloropropane were also quantified to be emitting from CPI closedcell foam. The emission rates for 1,2 dichloropropane was similar for the non-ideal and CPI foams over the duration of the experiments (Figure 9). However, the emission rates of 1,4 dioxane was approximately an order of magnitude higher for the non-ideal foam compared to the CPI foam. 


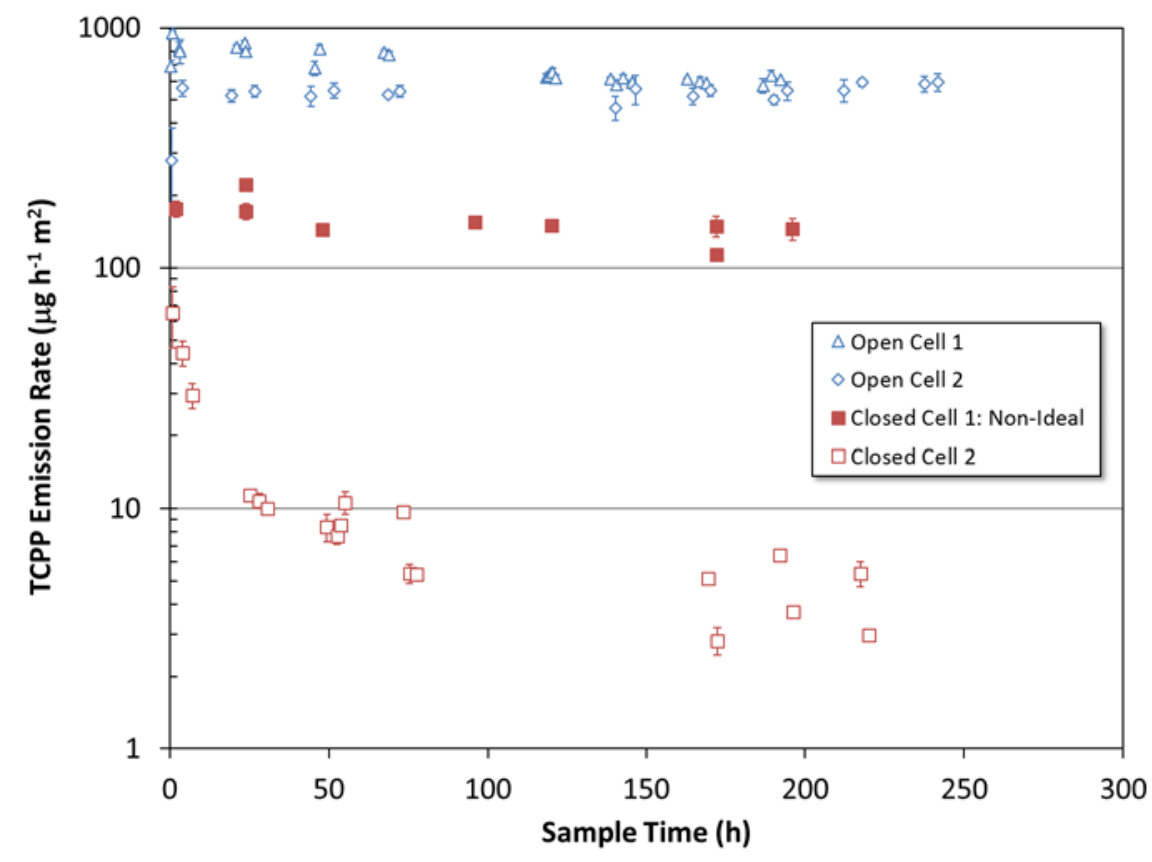

Figure 8. TCPP emission rates for different samples. Error bars show the standard error for each sampling time. Vertical axis is a logarithmic scale. Comparison data from Poppendieck et. al. 2016.

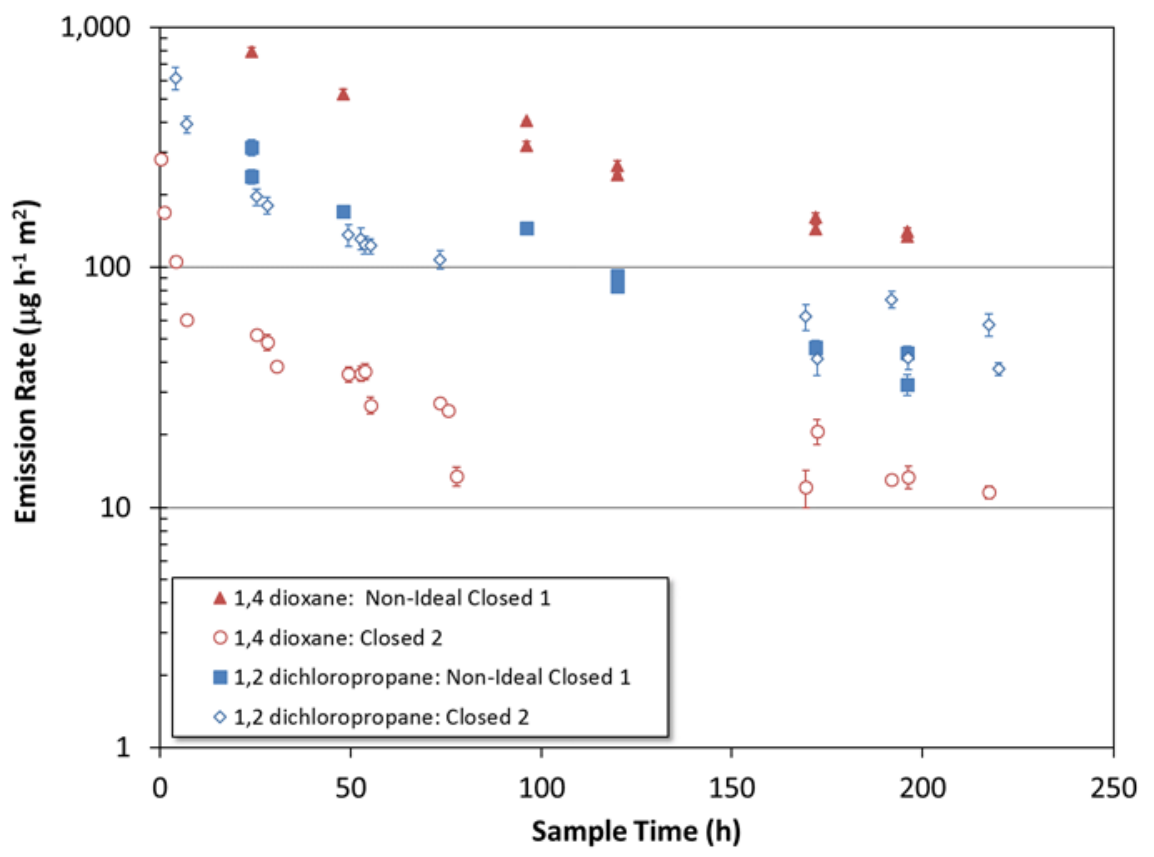

Figure 9. Emission Rates for 1,4 dioxane and 1,2 dichloropropane for tested non-ideal foam (Closed 1) compared to CPI closed-cell foam (Closed 2). Error bars show the standard error for each sampling time. Vertical axis is a logarithmic scale. Comparison data from Poppendieck et. al. 2016. 


\section{Conclusions}

There is limited published data on emissions from SPF foams. This study sought to expand the known data by analysing a non-ideal foam sample. This foam had the following features:

1. SPF from location 1 had a density that was roughly 1.7 times greater than average closedcell SPF. SPF from location 2 had a density that was roughly 1.2 times greater than average closed-cell SPF.

2. Over 80 peaks representing different chemicals were recognized as emitting from the tested non-ideal SPF. A total of 17 chemicals were relatively substantial in size and identified with a spectrum match. Seven of those chemicals have not been identified in other SPF emission studies using a similar test method.

3. The concentrations of chemicals emitted from both location 1 and location 2 were similar.

4. The emission rates of six chemicals were quantified. The emission rates of all chemicals except for TCPP decreased in a negative exponential manner.

5. The emission rate of TCPP was relatively constant after 48 hours. This is in contrast to TCPP emission rates from other tested closed-cell foams.

The above conclusions on the differences between tested SPF samples in the present study and previous CPI foam indicate that the tested non-ideal SPF may have been misapplied. However, the results may simply reflect the fact that the tested SPF samples are different from CPI foam. More surveys on chemicals emitting from SPF in real buildings are needed to determine if the tested foam is indeed a misapplied foam. Emission rates in this document apply only to microchamber conditions. This data should not be used to predict full-scale emissions until further testing has determined mass transfer parameters.

\section{Disclaimer}

Certain trade names or company products are mentioned in the text to specify adequately the experimental procedure and equipment used. In no case does such identification imply recommendation or endorsement by the National Institute of Standards and Technology, nor does it imply that the equipment is the best available for the purpose.

\section{Acknowledgements}

This work was funded in part by the U.S. Consumer Product Safety Commission (CPSC) under Interagency Agreement CPSC-I-14-0023.

\section{References}

Poppendieck, D.; Schlegel, M.; Connor, A.; Blickley, A. Flame Retardant Emissions from Spray Polyurethane Foam Insulation. Accepted for publication ASTM Selected Technical Papers. 2016. 